\title{
Developing brief versions of the Moral Foundations Vignettes using a genetic algorithm-based approach
}

\author{
Damien L. Crone ${ }^{1} \cdot$ Joshua J. Rhee ${ }^{2} \cdot$ Simon M. Laham ${ }^{3}$ \\ Accepted: 19 September 2020 / Published online: 1 October 2020 \\ (C) The Psychonomic Society, Inc. 2020
}

\begin{abstract}
The time-efficient assessment of moral values using systematically validated measures is a high priority in moral psychology research. However, few such options exist for researchers working with Moral Foundations Theory, one of the most popular theories in moral psychology. Across two samples totaling 1336 participants (756 Australian undergraduates and 580 American Mechanical Turk workers), we used a genetic algorithm-based (GA) approach to construct and validate abbreviated versions of the Moral Foundations Vignettes (MFV), a 90-item scale comprising vignettes of concrete violations of each of the six moral foundations. We constructed 36- and 18-item versions of the MFV, demonstrating close correspondence with the complete MFV, and adequate reliability, predictive validity, and factor-analytic goodness of fit for both abbreviated versions. Overall, the abbreviated scales achieve substantially reduced length with minimal loss of information, providing a useful resource for moral psychology researchers.
\end{abstract}

Keywords Moral psychology $\cdot$ Moral judgment $\cdot$ Scale abbreviation $\cdot$ Scale validation

\section{Introduction}

In recent decades, moral psychology has taken to describing individual variation in people's moral concerns. Most prominent among these descriptions is Moral Foundations Theory (MFT; Graham et al., 2013; Haidt \& Joseph, 2004), according to which differences in moral judgments can be explained by differential endorsement of five (or six) foundational moral values: Care, Fairness, Ingroup loyalty, respect for Authority, Purity, and Liberty. This constellation of moral values has been used to describe moral judgments of

Electronic supplementary material The online version of this article (https://doi.org/10.3758/s13428-020-01489-y) contains supplementary material, which is available to authorized users.

Damien L. Crone

dcrone@sas.upenn.edu

1 University of Pennsylvania, Philadelphia, PA, USA

2 University of Melbourne, Parkville, Australia

3 University of Melbourne, Parkville, Australia phenomena ranging from real-life political issues (Koleva et al., 2012) to responses to sacrificial moral dilemmas (Crone \& Laham, 2015), and much else besides.

To date, three systematically validated questionnaire measures have been developed to measure endorsement of these different moral values. Most prominent among these are the Moral Foundations Questionnaire (MFQ; Graham et al., 2011) and Moral Foundations Sacredness Scale (Graham \& Haidt, 2012). Recently, an independent group of researchers developed the Moral Foundations Vignettes (MFV; Clifford, Iyengar, Cabeza, \& Sinnott-Armstrong, 2015), comprising 90 standardized, concrete moral transgressions, covering all six foundations (unlike the MFQ and MFSS, which cover the original five), ${ }^{1}$ assessing the extent to which respondents disapprove of violations of each foundation.

Although the MFV benefits from being long enough to yield reliable scores, its length has the obvious draw-

\footnotetext{
${ }^{1}$ MFQ-style items for Liberty do exist as a separate measurement (Iyer, Koleva, Graham, Ditto, \& Haidt, 2012); however; their factor structure (particularly with respect to the rest of the MFQ) has not received extensive attention.
} 
back of rendering the scale impractically long in many settings, prompting researchers to administer subsets of the items to reduce test length (e.g., Ottaviani, Mancini, Provenzano, Collazzoni, \& D’Olimpio, 2018; Wagemans, Brandt, \& Zeelenberg, 2018). ${ }^{2}$ Without a systematically abbreviated scale however, researchers will tend to use ad hoc abbreviations that may vary in their quality, and insofar as researchers use different item subsamples, results will not be readily comparable.

Given the promise of the MFV as a measure of concern about the six moral foundations, and given that no abbreviated version of the MFV exists, we aimed to create abbreviated MFV scales using rigorous scaleshortening methods to allow time-efficient, standardized assessment of the extent to which people disapprove of violations of the six moral foundations.

\section{Method}

\section{Participants}

We used two samples to develop and validate the abbreviated versions of the MFV. The first sample (henceforth labeled UG) comprised 756 Australian undergraduate psychology students (age $M=19.56, S D=3.85$, range 17 to 51) participating in a larger study for course credit between January 2015 and November 2016. The second sample (labeled AMT) comprised 580 Mechanical Turk workers (age $M=34.01, S D=$ 10.07, range 17 to 71 ), recruited between May 2017 and November 2017. Additional demographic information is available in Supplementary Tables S1 and S2.

\section{Sample partitioning}

In developing an abbreviated version of the MFV, we identified three goals that had to be traded off against one another. First, it is desirable to have a sufficiently large training sample to ensure that sampling error has minimal influence on the item selection process. Second, it is desirable to have a sufficiently diverse sample for the abbreviation process to ensure that the abbreviated scales are not just optimized for use in a single, narrow population or context. Finally, related to the second goal, it is desirable to have large quantities of independent data for cross-validation to provide a concrete test of generalizability.

\footnotetext{
${ }^{2}$ A recent review of scale lengths in papers published in the Journal of Personality and Social Psychology revealed that the average scale length for measures of latent constructs is less than seven items (Flake, Pek, \& Hehman, 2017). This suggests that many researchers would be reluctant to use the average 15 items per moral foundation required by the full MFV.
}

To strike a balance between these competing goals, we assembled a balanced "training sample" comprising 800 participants (i.e., 400 randomly drawn from each of the two samples) which we used to select items and to perform the majority of our initial analyses (described below). The remaining participants form the two "validation samples" (UG validation sample $N=356$; AMT validation sample $N=180$ ) in which we replicated the same analyses as conducted in the training sample.

\section{Materials}

Participants completed the 90-item version of the Moral Foundations Vignettes (Clifford et al., 2015). Vignettes in the MFV describe third-person moral violations, each relating to a specific moral foundation (e.g., "You see a student copying a classmate's answer sheet on a makeup final exam" for Fairness). For each item, participants rated how morally wrong the behavior is on a 5-point scale ("Not at all wrong" to "Extremely wrong").

Additionally, in the UG sample, participants completed a survey of political issue positions on 13 issues (e.g., abortion) taken from Koleva et al. (2012). Participants rated the issues on a 5-point scale ("Morally acceptable in most or all cases" to "Morally wrong in most or all cases"). Given MFT's widespread use as an explanation for political differences (Graham et al., 2013), these issues served as criterion variables with which to compare the abbreviated versions of the MFV.

Further details of the materials (including descriptions of subtle variations in question wording across samples) are available in the Supplementary Materials.

\section{Scale abbreviation procedure}

To abbreviate the scale, we used the GAabbreviate package for R (Sahdra, Ciarrochi, Parker, \& Scrucca, 2016). GAabbreviate uses a genetic algorithm (GA) to iterate through a large number of possible shortened scales to try to find the abbreviated scale that maximizes explained variance in the complete scale (for further details, see Sahdra et al., 2016; Schroeders, Wilhelm, \& Olaru, 2016; Yarkoni, 2010). GA-based approaches have been shown to be preferable to common manual scaleshortening strategies such as selecting items with the highest loadings, both in terms of maximizing explained variance, and in terms of performance on conventional scale evaluation metrics such as factor analytic fit indices (Schroeders et al., 2016). See the analysis code available at https://osf.io/cmwpv/ for further details.

The recommended MFV set contains 90 vignettes overall, covering all six foundations (including 
Liberty), and containing three Care-related subscales (Animal harm, Human emotional harm, and Human physical harm). For the Care foundation, we created an overall Care scale by averaging the three Care subscales. ${ }^{3}$ We attempted to construct two abbreviated scales with three and six items per foundation, respectively, choosing three items as the shortest version, given such is one more than the minimum number of indicators per factor typically required to identify a CFA model (Kenny \& Milan, 2012). Moreover, as shown in the analyses below, any further reduction would be unlikely to yield a usable measure for such broad constructs. Our choice of six items as the longer abbreviated scale was motivated by a desire to make a short scale with minimal loss of information compared to the full MFV, but which is also of comparable length to the commonly used and substantially shorter MFQ (which also uses six items per foundation compared to the MFV's average of 15).

\section{Results}

The final items for both abbreviated scales are presented in the Appendix. ${ }^{4}$ Our primary analyses consisted of four components: (1) examining correlations between the original and abbreviated scales, (2) computing scale reliabilities, (3) performing confirmatory factor analysis (CFA), and (4) estimating a set of regression models in which the different MFV scale versions are used to predict political issue positions.

Correlations between the original and abbreviated 3and 6-item scales are respectively shown in Figs. 1 and 2 for the training sample, and in Table 1 for the two validation samples. Correlations between the complete and abbreviated scales were all extremely high ( $r$ s respectively $\geq .95$ and .91 for the 6- and 3-item scales in the training sample, and $\geq .91$ and .86 for the 6 - and 3 item scales across the two validation samples).

Next, we compared the reliabilities of the complete and abbreviated scales, as shown in Table 2 . Unsurprisingly, reliabilities for the abbreviated scales tended to be slightly lower (given that scale length is

\footnotetext{
${ }^{3}$ If we instead averaged over all Care items to create a Care scale, the Care facets would be weighted in proportion to the number of items measuring each facet, implying that Animal harm is more than twice as important as Physical harm, and Emotional harm more than five times so (simply because of the unbalanced number of items). Given that we are aware of no literature justifying such an imbalanced weighting of different facets of Care, and given that measures such as the MFQ emphasize breadth, we opted to weight each of the three facets equally.

${ }^{4}$ Note that the 3 -item version only partially overlaps with the 6-item version: 15 of the 18 items in the 3 -item version appear amongst the 36 items in the 6item version.
}

used in the computation of Cronbach's alpha). However, the reliabilities of the 6-item scales were comparable to the MFQ (which contains the same number of items per foundation). ${ }^{5}$ Reliabilities for the 3 -item scales were slightly lower than the 6-item scales, but comparable to the MFQ. In a substantial number of cases, mean inter-item correlations tended to be slightly higher for both abbreviated scales vs. the complete scales. Thus, the abbreviated scales seem to be adequately reliable despite their brevity.

Next we performed CFAs for the complete and abbreviated scales, summarized in Table 3. Although the models for the scales of differing lengths are not formally comparable given that they are based on nonidentical covariance matrices, the abbreviated measure performed identically or slightly better according to the root mean square error of approximation (RMSEA), and substantially better according to the comparative fit index (CFI) and Tucker-Lewis index (TLI). Note also that the abbreviated versions approached or exceeded conventional criteria for well-fitting models $($ RMSEA $<.06$; CFI $>.95 ; \mathrm{Hu} \&$ Bentler, 1999). For additional CFA results such as factor loadings, see the $\mathrm{R}$ Notebook available at https://osf.io/cmwpv/.

Finally, to test the construct validity of the abbreviated scales, we fitted a set of ordinary least squares (OLS) regressions in which scores on all six moral foundations were used to predict UG participants' positions on various political issues (i.e., 39 models: 3 scale versions by 13 political issues). ${ }^{6}$ The amount of explained variance for each of the three scale versions across these issues is summarized in Fig. 3 (analogous structural equation models are described in the SI). Across the set of regressions, the 6- and 3-item scales explained slightly less variance in the criterion variables. Despite the substantial reduction in length, however, the scales still achieved average $R^{2}$ values of $90 \%$ and $87 \%$ of the full scale across the 13 issues, once again suggesting that much of the information in the complete scales is retained despite dramatic reductions in scale length.

\footnotetext{
${ }^{5}$ In the original MFQ validation paper, alphas across the five subscales ranged from .65 (Fairness) to .84 (Purity), with an average of .73 (see Table 1 in Graham et al., 2011), while a meta-analysis of MFQ subscale reliabilities by Tamul et al. (2020) yielded estimates between .64 (Fairness) and .83 (Purity). It is also worth noting that alphas for the 3-item scales described here are substantially better than the 15 -item MFQ described in Table 1 of Graham et al. (2011), whose alphas ranged from .39 to .70 , with an average of .59 .

${ }^{6}$ Note that unlike the preceding analyses, these analyses were conducted just once, on the entire UG sample (because such data are only available in this sample). These analyses are thus not replicated in the AMT sample.
} 
Care

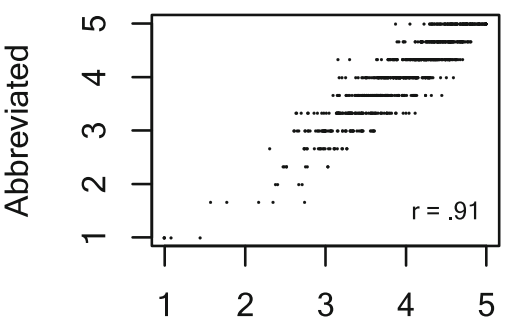

Ingroup

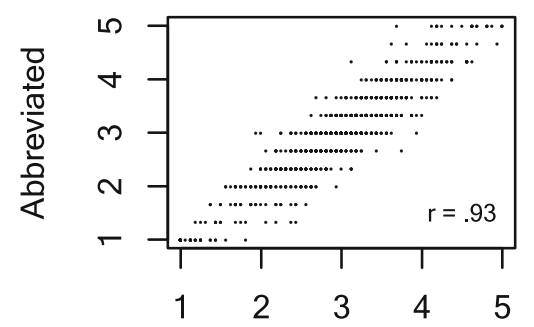

Purity

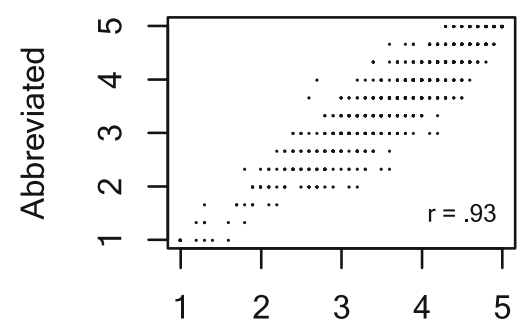

Complete

\section{Fairness}

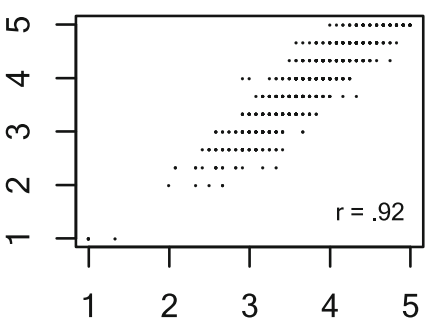

Authority

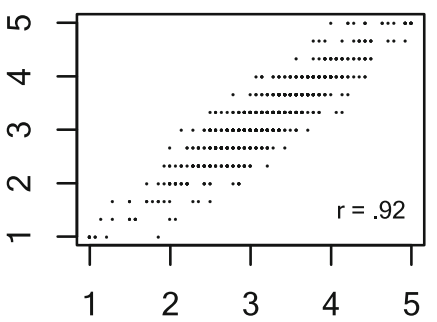

Liberty

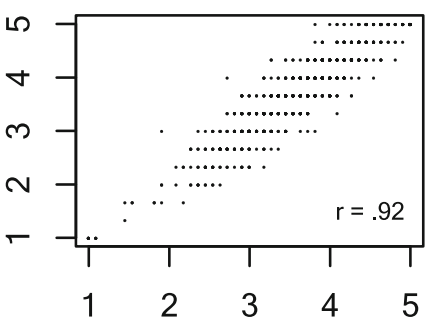

Complete

Fig 1 Training sample correlations between abbreviated 3-item scale and complete scale. Each cell depicts the association between each participant's scores on the complete and 3 -item version scales for a given moral foundation

\section{Discussion}

The present study aimed to create abbreviated versions of the MFV to allow time-efficient, standardized assessment of people's endorsement of the six moral foundations. To this end, we constructed two abbreviated versions of the MFV comprising $40 \%$ and $20 \%$ of the original items. Across wide-ranging analyses, these shortened scales corresponded closely to the original scales, and exhibited promising levels of reliability, as well as factor analytic and predictive validity. Here, we close with a brief discussion of recommendations for, and limitations of, use of these new abbreviated scales.

Firstly, we note that the abbreviated scales we present were validated in an Australian undergraduate sample and American Mechanical Turk sample. One obvious direction for future studies is to validate these scales in other populations. However, we believe our results provide strong evidence for the validity of the abbreviated scales in samples that (for better or worse) resemble a substantial proportion of the most frequently studied populations in psychological research. 
Care

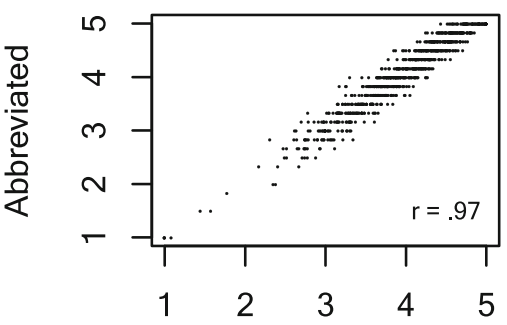

Ingroup

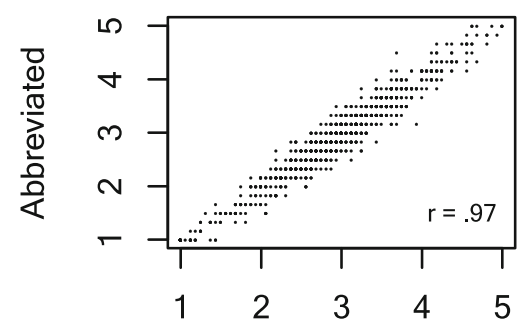

Purity

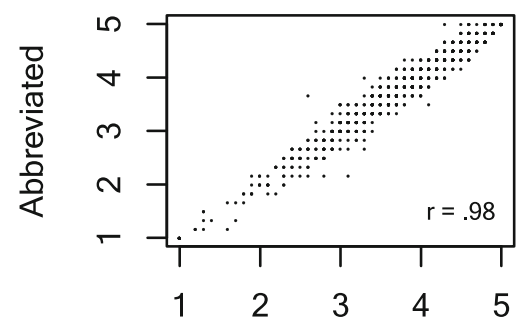

Complete
Fairness

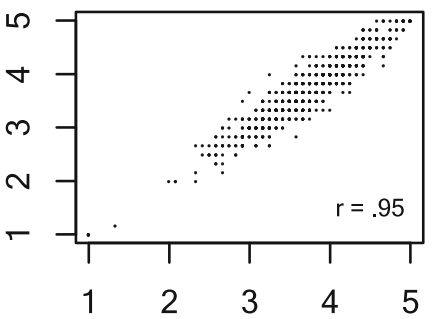

Authority

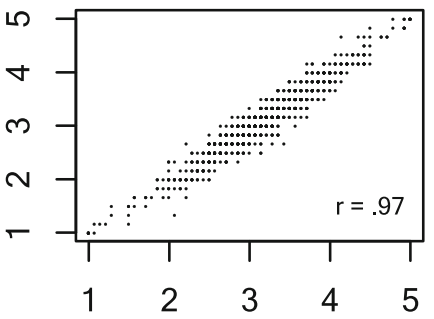

Liberty

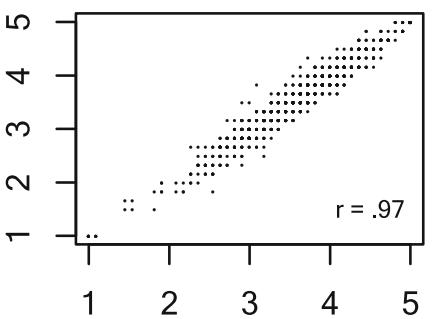

Complete

Fig. 2 Training sample correlations between abbreviated 6-item scale and complete scale. Each cell depicts the association between each participant's scores on the complete and 6-item version scales for a given moral foundation

Table 1. Validation sample correlations between complete and analogous abbreviated scales

\begin{tabular}{lllll}
\hline & \multicolumn{2}{l}{ 6-item } & & \multicolumn{2}{l}{ 3-item } \\
\cline { 2 - 3 } \cline { 5 - 5 } & UG & AMT & UG & AMT \\
\hline Care & .95 & .97 & .88 & .93 \\
Fairness & .91 & .97 & .86 & .93 \\
Ingroup & .94 & .97 & .87 & .94 \\
Authority & .95 & .98 & .89 & .94 \\
Purity & .97 & .98 & .89 & .95 \\
Liberty & .96 & .98 & .89 & .93 \\
\hline
\end{tabular}

Note: Each cell represents the correlation between a given complete MFV subscale (e.g., Care) and its corresponding 3- or 6-item counterpart in either the Undergraduate (UG) or Mechanical Turk (AMT) sample 
Table 2. Scale reliabilities

\begin{tabular}{|c|c|c|c|c|c|c|c|c|c|}
\hline & \multicolumn{3}{|c|}{ Complete } & \multicolumn{3}{|c|}{ Abbreviated (6-item) } & \multicolumn{3}{|c|}{ Abbreviated (3-item) } \\
\hline & Train & UG (test) & AMT (test) & Train & UG (test) & AMT (test) & Train & UG (test) & AMT (test) \\
\hline \multicolumn{10}{|l|}{ Alpha } \\
\hline Care & .95 & .93 & .96 & .82 & .78 & .87 & .65 & .63 & .72 \\
\hline Fairness & .89 & .84 & .93 & .80 & .73 & .88 & .77 & .66 & .82 \\
\hline Ingroup & .94 & .92 & .96 & .87 & .81 & .91 & .78 & .62 & .83 \\
\hline Authority & .93 & .91 & .95 & .85 & .80 & .89 & .76 & .70 & .83 \\
\hline Purity & .90 & .87 & .93 & .85 & .81 & .89 & .72 & .63 & .76 \\
\hline Liberty & .90 & .86 & .92 & .83 & .77 & .86 & .75 & .68 & .76 \\
\hline \multicolumn{10}{|c|}{ Omega total } \\
\hline Care & .95 & .94 & .96 & .82 & .78 & .87 & .65 & .64 & .72 \\
\hline Fairness & .89 & .84 & .93 & .81 & .74 & .88 & .77 & .67 & .83 \\
\hline Ingroup & .94 & .92 & .96 & .87 & .81 & .91 & .78 & .62 & .83 \\
\hline Authority & .93 & .91 & .95 & .85 & .80 & .89 & .77 & .71 & .83 \\
\hline Purity & .90 & .87 & .94 & .85 & .81 & .89 & .73 & .64 & .76 \\
\hline Liberty & .90 & .86 & .92 & .83 & .78 & .86 & .75 & .69 & .76 \\
\hline \multicolumn{10}{|c|}{ Mean inter-item correlation } \\
\hline Care & .40 & .35 & .44 & .43 & .37 & .52 & .38 & .36 & .46 \\
\hline Fairness & .40 & .31 & .53 & .40 & .31 & .55 & .53 & .40 & .61 \\
\hline Ingroup & .51 & .41 & .60 & .53 & .42 & .62 & .54 & .35 & .61 \\
\hline Authority & .49 & .41 & .58 & .49 & .40 & .58 & .52 & .44 & .61 \\
\hline Purity & .49 & .39 & .59 & .48 & .41 & .57 & .47 & .37 & .51 \\
\hline Liberty & .45 & .35 & .52 & .46 & .36 & .51 & .50 & .41 & .51 \\
\hline
\end{tabular}

Table 3. Goodness-of-fit statistics for confirmatory factor analyses

\begin{tabular}{llll}
\hline & Complete & $\begin{array}{l}\text { Abbreviated } \\
(6 \text {-item })\end{array}$ & $\begin{array}{l}\text { Abbreviated } \\
(3 \text {-item })\end{array}$ \\
\hline Training Sample & & & \\
Chi-square & 12508.396 & 1796.951 & 327.428 \\
df & 3900 & 545 & 120 \\
$p$ & $<.001$ & $<.001$ & $<.001$ \\
SRMR & .066 & .055 & .043 \\
RMSEA & .053 & .054 & .046 \\
[95\% CI] & {$[.051, .054]$} & {$[.051, .056]$} & {$[.040, .053]$} \\
CFI & .801 & .901 & .961 \\
TLI & .795 & .892 & .950 \\
UG Sample & & & \\
Chi-square & 7512.254 & 988.755 & 209.763 \\
df & 3900 & 545 & 120 \\
$p$ & $<.001$ & $<.001$ & $<.001$ \\
SRMR & .070 & .058 & .048 \\
RMSEA & .051 & .048 & .046 \\
[95\% CI $]$ & {$[.049, .053]$} & {$[.043, .053]$} & {$[.035, .056]$} \\
CFI & .764 & .894 & .945 \\
TLI & .758 & .884 & .930 \\
AMT Sample & & & \\
Chi-square & 8161.59 & 1076.758 & 233.308 \\
df & 3900 & 545 & 120 \\
$p$ & $<.001$ & $<.001$ & $<.001$ \\
SRMR & .090 & .073 & .059 \\
RMSEA & .078 & .074 & .072 \\
[95\% CI $]$ & {$[.076, .080]$} & {$[.067, .080]$} & {$[.058, .086]$} \\
CFI & .705 & .868 & .926 \\
TLI & .697 & .856 & .906 \\
\hline
\end{tabular}

SRMR = Standardized Root Mean Square Residual; RMSEA = Root Mean Square Error of Approximation; CFI = Comparative Fit Index; TLI $=$ Tucker-Lewis Index
Overall, we recommend the 6-item version of the MFV for accurate results with substantially reduced testing time. While the 3-item scale does largely possess adequate psychometric properties (especially in comparison to shortened MFQ scales of comparable length), it is limited by its somewhat lower reliability. The drawbacks of the lower reliabilities can be partly remedied by using latent variable models (Cole \& Preacher, 2014; Westfall \& Yarkoni, 2016). ${ }^{7}$ Finally, we note that brief scales might not be suitable for all settings. In some cases, researchers will have strict time constraints yet also want to collect more observations to enhance precision and generalizability. In such contexts, researchers might consider other time-efficient alternatives such as image stimuli (Crone, Bode, Murawski, \& Laham, 2018). In many cases, however, we believe the abbreviated MFV scales presented here will be a useful resource for moral psychology researchers.

Open practices statement The study reported in this paper was not preregistered. Analysis code and data from the UG sample are available at https://osf.io/cmwpv/. Data from the AMT sample is stored in a separate OSF repository available upon request.

\footnotetext{
${ }^{7}$ As shown in the Supplementary Materials, however, the 3-item scales may be vulnerable to overly optimistic $R^{2}$ estimates in SEMs, compared to the longer scales.
} 

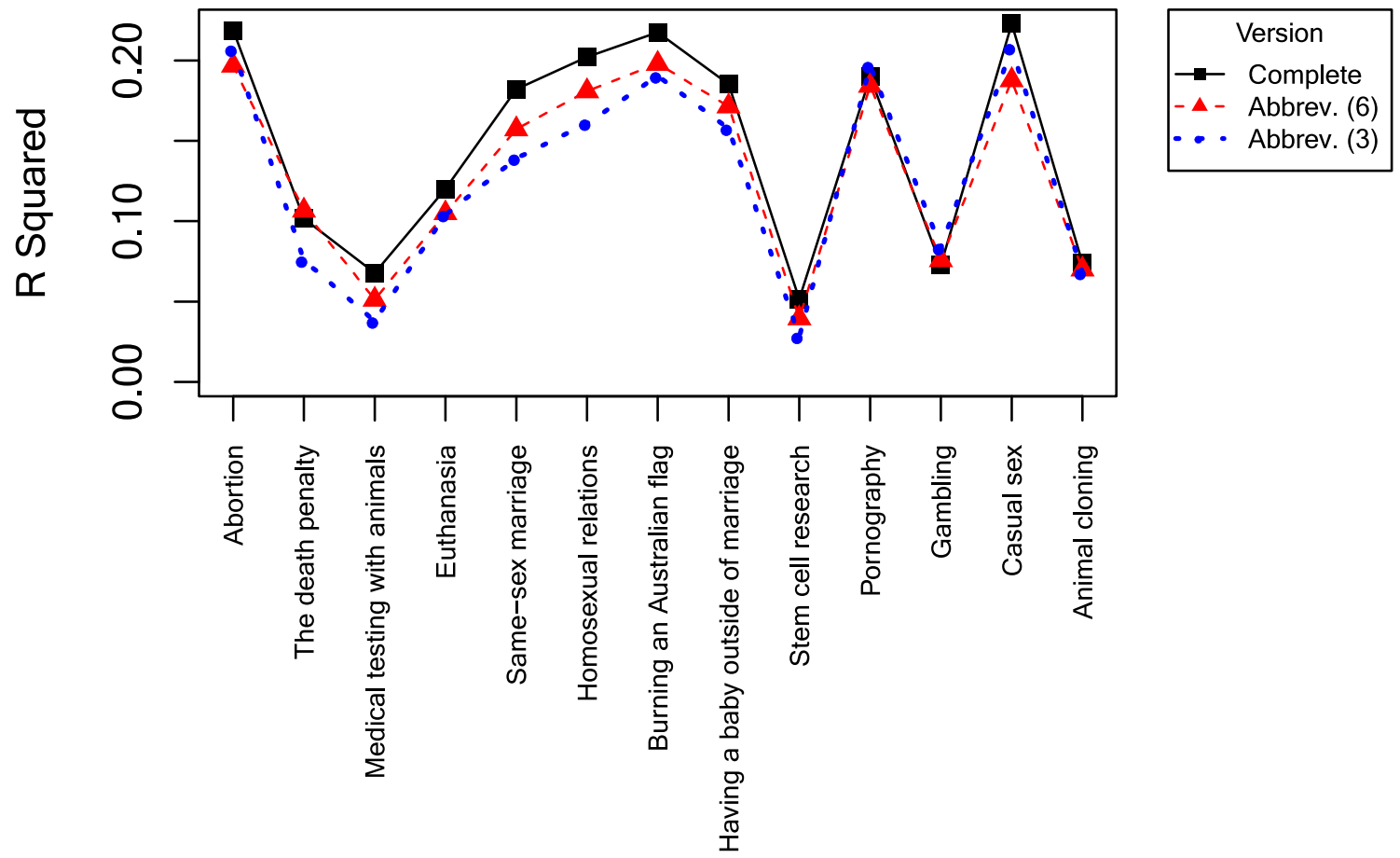

Issue

Fig. 3 R-Squared estimates from OLS regressions predicting issue positions based on moral foundation scores

\section{Appendix}

Table 4. Final items for abbreviated 6-item scale

Foundation / Item

Item \#

Item

Care

5

18

20

25

26

27

Fairness

29

31

33

34

35

36

Liberty

40

42

43

46

49

50

Authority

52

54

57

59

a boy telling a woman that she looks just like her overweight bulldog a woman throwing her cat across the room for scratching the furniture a boy throwing rocks at cows that are grazing in the local pasture a boy placing a thumbtack sticking up on the chair of another student a teacher hitting a student's hand with a ruler for falling asleep in class a woman spanking her child with a spatula for getting bad grades in school

a runner taking a shortcut on the course during the marathon in order to win a soccer player pretending to be seriously fouled by an opposing player a referee intentionally making bad calls that help his favored team win a judge taking on a criminal case although he is friends with the defendant an employee lying about how many hours she worked during the week a boy skipping to the front of the line because his friend is an employee

a man telling his fiancée that she has to switch to his political party a man telling his girlfriend that she must convert to his religion a mother telling her son that she is going to choose all of his friends a woman pressuring her daughter to become a famous evening news anchor a father requiring his son to take up the family restaurant business a pastor banning his congregants from wearing bright colors in the church

a girl repeatedly interrupting her teacher as he explains a new concept a teenage girl coming home late and ignoring her parents' strict curfew a man secretly watching sports on his cell phone during a pastor's sermon a teaching assistant talking back to the teacher in front of the classroom 
Table 4. (continued)

\begin{tabular}{ll}
\hline $\begin{array}{l}\text { Foundation / } \\
\text { Item \# }\end{array}$ & Item \\
\hline 62 & a man turn his back and walk away while his boss questions his work \\
64 & a star player ignoring her coach's order to come to the bench during a game \\
Ingroup & a former Army General from your country saying publicly he would never buy any of your country's products \\
67 & a man leaving his family business to go work for their main competitor \\
70 & the class president saying on TV that her rival college is a better school \\
73 & a college president singing a rival school's fight song during a pep rally \\
75 & one of your countrymen telling foreigners that your country is an evil force in the world \\
77 & the coach's wife sponsoring a bake sale for her husband's rival team \\
78 & \\
Purity & a man having sex with a frozen chicken before cooking it for dinner \\
81 & a drunk elderly man offering to have oral sex with anyone in the bar \\
82 & a man in a bar using his phone to watch people having sex with animals \\
83 & a woman having intimate relations with a recently deceased loved one \\
84 & a story about a remote tribe eating the flesh of their deceased members \\
87 & a single man ordering an inflatable sex doll that looks like his secretary \\
90 &
\end{tabular}

Note: All items begin with "You see ..." (omitted above for brevity). Items use non-American wording employed for the UG sample. Item number represents location in the complete version of the MFV

Table 5. Final items for abbreviated 3-item scale

\begin{tabular}{|c|c|}
\hline $\begin{array}{l}\text { Foundation / } \\
\text { Item \# }\end{array}$ & Item \\
\hline \multicolumn{2}{|l|}{ Care } \\
\hline 5 & a boy telling a woman that she looks just like her overweight bulldog \\
\hline 20 & a boy throwing rocks at cows that are grazing in the local pasture \\
\hline 27 & a woman spanking her child with a spatula for getting bad grades in school \\
\hline \multicolumn{2}{|l|}{ Fairness } \\
\hline 29 & a runner taking a shortcut on the course during the marathon in order to win \\
\hline 33 & a referee intentionally making bad calls that help his favored team win \\
\hline 35 & an employee lying about how many hours she worked during the week \\
\hline \multicolumn{2}{|l|}{ Liberty } \\
\hline 40 & a man telling his fiancée that she has to switch to his political party \\
\hline 43 & a mother telling her son that she is going to choose all of his friends \\
\hline 48 & a mother forcing her daughter to enroll as a pre-med student in college \\
\hline \multicolumn{2}{|l|}{ Authority } \\
\hline 54 & a teenage girl coming home late and ignoring her parents' strict curfew \\
\hline 60 & a staff member talking loudly and interrupting the mayor's speech to the public \\
\hline 62 & a man turn his back and walk away while his boss questions his work \\
\hline \multicolumn{2}{|l|}{ Ingroup } \\
\hline 67 & a former Army General from your country saying publicly he would never buy any of your country's products \\
\hline 72 & a head cheerleader booing her high school's team during a homecoming game \\
\hline 78 & the coach's wife sponsoring a bake sale for her husband's rival team \\
\hline \multicolumn{2}{|l|}{ Purity } \\
\hline 82 & a drunk elderly man offering to have oral sex with anyone in the bar \\
\hline 83 & a man in a bar using his phone to watch people having sex with animals \\
\hline 87 & a story about a remote tribe eating the flesh of their deceased members \\
\hline
\end{tabular}

Note: All items begin with "You see ..." (omitted above for brevity). Items use non-American wording employed for the UG sample. Item number represents location in the complete version of the MFV 


\section{References}

Clifford, S., Iyengar, V., Cabeza, R., \& Sinnott-Armstrong, W. (2015). Moral Foundations Vignettes: A standardized stimulus database of scenarios based on moral foundations theory. Behavior Research Methods, 47(4), 1178-1198. https://doi.org/10.3758/s13428-0140551-2

Cole, D. A., \& Preacher, K. J. (2014). Manifest variable path analysis: Potentially serious and misleading consequences due to uncorrected measurement error. Psychological Methods, 19(2), 300-315. https:// doi.org/10.1037/a0033805

Crone, D. L., Bode, S., Murawski, C., \& Laham, S. M. (2018). The Socio-Moral Image Database (SMID): A novel stimulus set for the study of social, moral and affective processes. PLOS ONE, 13(1), e0190954. https://doi.org/10.1371/journal.pone.0190954

Crone, D. L., \& Laham, S. M. (2015). Multiple moral foundations predict responses to sacrificial dilemmas. Personality and Individual Differences, 85(4), 60-65. https://doi.org/10.1016/j.paid.2015.04. 041

Flake, J. K., Pek, J., \& Hehman, E. (2017). Construct validation in social and personality research: Current practice and recommendations. Social Psychological and Personality Science, 8(4), 370-378. https://doi.org/10.1177/1948550617693063

Graham, J., \& Haidt, J. (2012). Sacred values and evil adversaries: A moral foundations approach. In M. Mikulincer \& P. R. Shaver (Eds.), The Social Psychology of Morality: Exploring the Causes of Good and Evil (pp. 1-26). New York: APA Books.

Graham, J., Haidt, J., Koleva, S. P., Motyl, M., Iyer, R., Wojcik, S. P., \& Ditto, P. H. (2013). Moral Foundations Theory: The pragmatic validity of moral pluralism. Advances in Experimental Social Psychology, 47, 55-130. https://doi.org/10.1016/B978-0-12407236-7.00002-4

Graham, J., Nosek, B. A., Haidt, J., Iyer, R., Koleva, S. P., \& Ditto, P. H. (2011). Mapping the moral domain. Journal of Personality and Social Psychology, 101(2), 366-385. https://doi.org/10.1037/ a0021847

Haidt, J., \& Joseph, C. M. (2004). Intuitive ethics: How innately prepared intuitions generate culturally variable virtues. Daedalus, 133(4), 5566. https://doi.org/10.1162/0011526042365555

Hu, L., \& Bentler, P. M. (1999). Cutoff criteria for fit indexes in covariance structure analysis: Conventional criteria versus new alternatives. Structural Equation Modeling, 6(1), 1-55. https://doi.org/10. 1080/10705519909540118

Iyer, R., Koleva, S. P., Graham, J., Ditto, P. H., \& Haidt, J. (2012). Understanding libertarian morality: The psychological dispositions of self-identified libertarians. PLOS ONE, 7(8), e42366. https://doi. org/10.1371/journal.pone.0042366

Kenny, D. A., \& Milan, S. (2012). Identification: A nontechnical discussion of a technical issue. In R. H. Hoyle (Ed.), Handbook of Structural Equation Modeling (pp. 145-163). Guilford Press. Retrieved from https://psycnet.apa.org/record/2012-16551-009

Koleva, S. P., Graham, J., Iyer, R., Ditto, P. H., \& Haidt, J. (2012). Tracing the threads: How five moral concerns (especially Purity) help explain culture war attitudes. Journal of Research in Personality, 46(2), 184-194. https://doi.org/10.1016/j.jrp.2012.01. 006

Ottaviani, C., Mancini, F., Provenzano, S., Collazzoni, A., \& D’Olimpio, F. (2018). Deontological morality can be experimentally enhanced by increasing disgust: A transcranial direct current stimulation study. Neuropsychologia, 119, 474-481. https://doi.org/10.1016/j. neuropsychologia.2018.09.009

Sahdra, B. K., Ciarrochi, J., Parker, P., \& Scrucca, L. (2016). Using Genetic Algorithms in a Large Nationally Representative American Sample to Abbreviate the Multidimensional Experiential Avoidance Questionnaire. Frontiers in Psychology, 7. https://doi. org/10.3389/fpsyg.2016.00189

Schroeders, U., Wilhelm, O., \& Olaru, G. (2016). Meta-heuristics in short scale construction: Ant colony optimization and genetic algorithm. PLoS ONE, 11(11), e0167110. https://doi.org/10.1371/journal. pone. 0167110

Tamul, D., Elson, M., Ivory, J., Hotter, J., Lanier, M., Wolf, J., \& Martínez-Carrillo, N. (2020). Moral Foundations' Methodological Foundations: A Systematic Analysis of Reliability in Research Using the Moral Foundations Questionnaire. PsyArXiv Preprint. https://doi.org/10.31234/osf.io/shcgv

Wagemans, F. M. A., Brandt, M. J., \& Zeelenberg, M. (2018). Disgust sensitivity is primarily associated with purity-based moral judgments. Emotion, 18(2), 277-289. https://doi.org/10.1037/ emo0000359

Westfall, J., \& Yarkoni, T. (2016). Statistically controlling for confounding constructs is harder than you think. PLoS ONE, 11(3), e0152719. https://doi.org/10.1371/journal.pone.0152719

Yarkoni, T. (2010). The abbreviation of personality, or how to measure 200 personality scales with 200 items. Journal of Research in Personality, 44(2), 180-198. https://doi.org/10.1016/j.jrp.2010.01. 002

Publisher's note Springer Nature remains neutral with regard to jurisdictional claims in published maps and institutional affiliations. 